\title{
Optical and XCT measurement of additively manufactured surfaces
}

\author{
Weidong Liu
}

University of Huddersfield, Queensgate, Huddersfield, West Yorkshire, HD1 3DH

A R T I C LE I N F O

Article history:

Received 18 October 2020

Received in revised form $\mathrm{O} 2$

February 2021

Accepted 16 April 2021

Keywords:

Additive manufacturing

Optical measurement

X-Ray CT

Surface metrology

\begin{abstract}
A B S T R A C T
This paper illustrates the comparative results of measuring the surface texture of additive manufacturing parts using optical techniques (Alicona G4) and Xray Computed Tomography (Nikon XTH225). The results of optical and XCT measurements are analysed respectively, per the surface texture parameters of ISO 25178-2. To target the most suitable measurement configuration, different measurements resulting from the same technique with various configurations are compared. The optical and XCT measured surfaces obtained via the targeted configuration parameters are then matched via surface registration to allow an accurate comparison in respect of both surface topography and its derived surface roughness parameters.
\end{abstract}

\section{Introduction}

Additive manufacturing (AM) is also known as $3 \mathrm{D}$ printing, and is paving the way towards the next industrial revolution - it has the potential to shift the paradigm of advanced manufacturing. AM is completed by selectively adding materials layer-bylayer. Compared with traditional subtractive manufacturing, AM has many advantages. The most obvious advantages are that it can reduce the number of parts required in the process, and can also control the shape of the fully enclosed space (Townsend et al., 2016), as shown in the internal lattice structure of Figure 1(a). This would be completely impossible with subtraction manufacturing. In the medical field, the artificial acetabular cup has open porous scaffolds that are conducive to cell attachment, as shown in Figure 1(b). The advantages of AM make it widely used in the field of health care products (Lou et al., 2019) \& (Vandenbroucke \& Kruth, 2007). In the aerospace industrial sector (Mehrpouya et al., 2019), AM is widely adopted as parts with complex geometries can be manufactured with less weight and better performance. See Figure 1(c) for an example of an AM built engine turbine blade. Although metal AM has many advantages, the as-built surface is very rough. In the medical field, using a metal component surface with higher surface roughness impacts upon the interaction between cells in artificial joints (Lou et al., 2019). In aerospace applications, the rough surface structure will result in large residual stresses, which means that certain parts have the risk of premature failure (Lou et al., 2019) \& (Thompson et al., 2018). The majority of AM parts must be polished before they can be put into use.

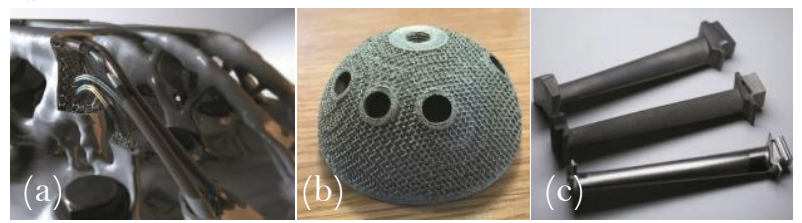

Fig. 1 Parts made by AM. (a): Internal lattice structure (Maskery et al., 2015), (b): Artificial joint with open-cell scaffold (Lou et al., 2019), (c): Aerospace engine parts (Additive Manufacturing, 2019).

The measurement and characterization of AM surface topography for product quality verification is very important (Lou et al., 2019). Various techniques are available for the measurement of AM surface texture, including tactile, optical and X-ray computed tomography (XCT). However, each measurement method is limited by its own shortcomings. According to the existing literature, optical techniques are the most popular method for AM surface texture measurement. In recent years, $\mathrm{XCT}$ is gaining more interest due to its ability to 
measure internal structures without breaking the part (Hiersemenzel, 2019) \& (Senin et al., 2017).

\section{AM and Surface Texture Measurement Techniques}

\section{Powder bed fusion}

In the field of metal AM, the powder bed fusion $(\mathrm{PBF})$ process is the most widely used (Townsend et al., 2016) \& (Lou et al., 2019). Its basic principle is described in Figure 2. As the laser or other heat source is irradiated to the designated area, the powder is melted under the action of high heat, and then solidified and fused with the movement of the heat source. After completing all the structures of the current layer, a new layer of powder will be evenly spread again on the structure area, and this operation is repeated layer by layer until all the structures are completed (Lou et al., 2019) \& (Sun et al., 2017). Since the metal at high temperature is prone to oxidation, the injection of inert gas into the internal chamber can prevent the occurrence of oxidation, and at the same time removing the condensate produced by the melted powder (Sun et al., 2017).

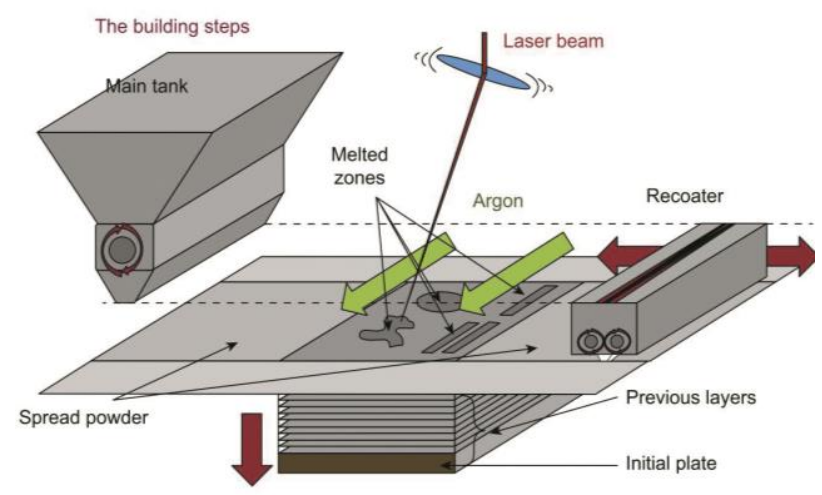

Fig. 2 Schematic illustration of the laser-based powder bed fusion process (Sun et al., 2017).

\section{Top \& Side surface for $A M$}

Due to the layer-by-layer nature of PBF process, we see an accumulation of un-melted particles at the junction of the edges of each layer, resulting in many spherical protrusions on the side surface. Therefore, in the same AM parts, the side surface is usually rougher than the top surface. On the top surface, the energy path left by the movement and the incompletely melted particle splash caused by high temperature are significant surface topography features. Figure 3 is the surface of the top and side views of the same part (Townsend et al., 2016), (Lou et al., 2019) \& (Leach et al., 2019).

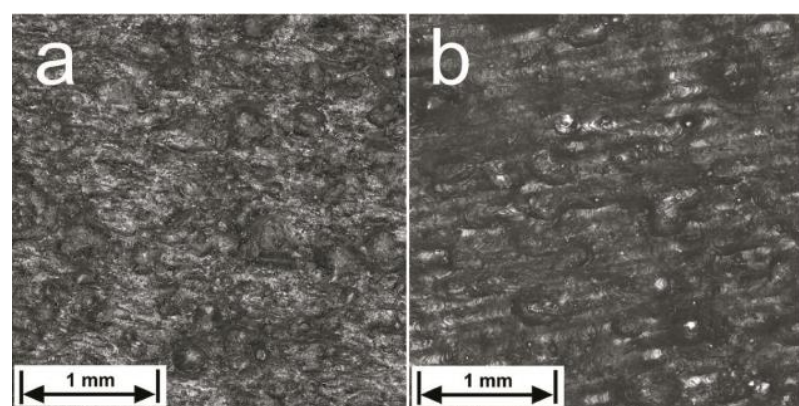

Fig. 3 Scanning electron microscope (SEM) measurement of $\mathrm{A} 1 \mathrm{Si} 1 \mathrm{OMg}$ Selective Laser Melting(SLM) component: (a) side surface, (b) top surface (Townsend et al., 2016).

\section{Focus variation microscopy (Optical)}

Optical microscope, nowadays, is widely used for areal surface texture measurement due to having the advantages of a non-contact, fast measurement speed and a high measurement resolution. Focus variation microscopy, hereinafter referred to as FVM, is also popular for the measurement of AM surfaces (Newton et al., 2019). It illuminates the experimental target through a light source, captures different degrees of reflected light through an optical sensor, and eventually converts this information into a height image. During the measurement process, the focal length of the optical device keeps changing, extracting images of different heights in the same position, and finally integrating the best results into complete data (Bruker alicona, n.d.) \& (Özel et al., 2019). This in turn means that each area can obtain a clear image, as shown in Figure 4. In addition, optical measurement is able to choose the appropriate illumination type according to the actual situation of the target part (Leach et al., 2019). The algorithm will convert all of the acquired data into matrix data, which can thereafter be exported into various different data formats.

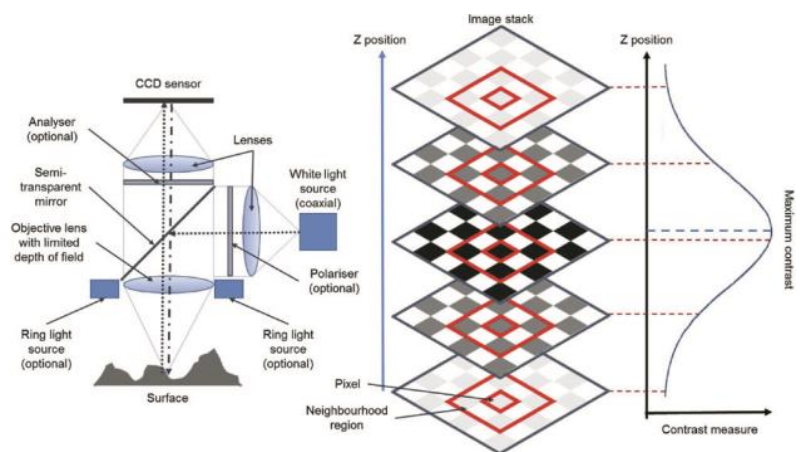

Fig. 4 Principle diagram of FVM (Newton et al., 2019). 
The measurement area size depends on the selected magnification, while the large image scanning can be achieved through the puzzle function (Özel et al., 2019). The area of interest can be flexibly selected, and it can be used together with the ring light to measure the tilt angle of more than $87^{\circ}$ (Bruker alicona, n.d.). However, there are a couple of challenges when employing FVM to the measurement of AM surfaces. In the face of complex surface topography, it is difficult for optical sensors to measure surface geometry. Due to the existence of deep ravines and high slope particles, the light cannot fully illuminate the surface or the detector has difficulty in capturing the reflected light source (Leach et al., 2019), (Newton et al., 2019), (Bruker alicona, n.d.), (Özel et al., 2019) \& (Hiersemenzel, 2019), which in turn causes partial data loss and the forming a non-measured-point (NMP). In addition, as Figure 5 shows, FVM cannot capture the characteristics of the re-entrant structure due to the excessive tilt angle.

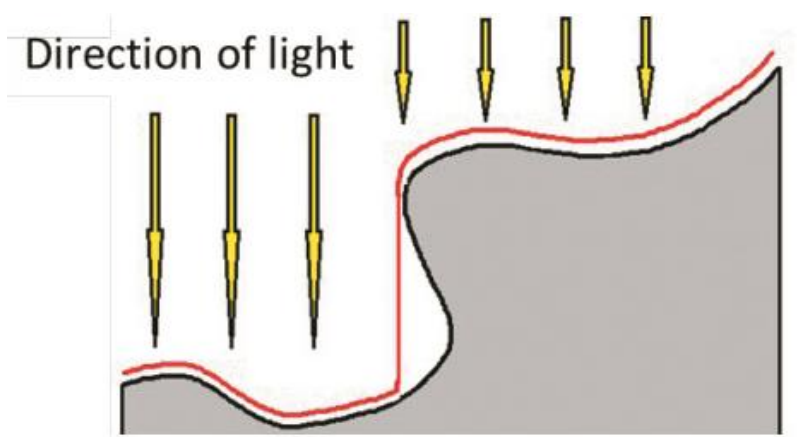

Fig. 5 Difference between the real surface and the measured surface for FVM (Hiersemenzel, 2019).

\section{X-ray Computed Tomography}

XCT uses X-ray radiation to illuminate the part. Part of the energy beam will be weakened on the way through the part, and the remaining beam will be captured by the detector. Each time the capture is completed, the part will rotate to a specific angle until all $360^{\circ}$ image captures are completed. The captured data undergoes a series of software operations in order to finally generate a $3 \mathrm{D}$ structure diagram (Lou et al., 2019), (Sun et al., 2012) \& (Thompson et al., 2018), as shown in Figure 6. Different measurement parameters, e.g. X-ray source current and acceleration voltage, the number of projections, the integration time, etc. will all produce different results (Leach et al., 2019).

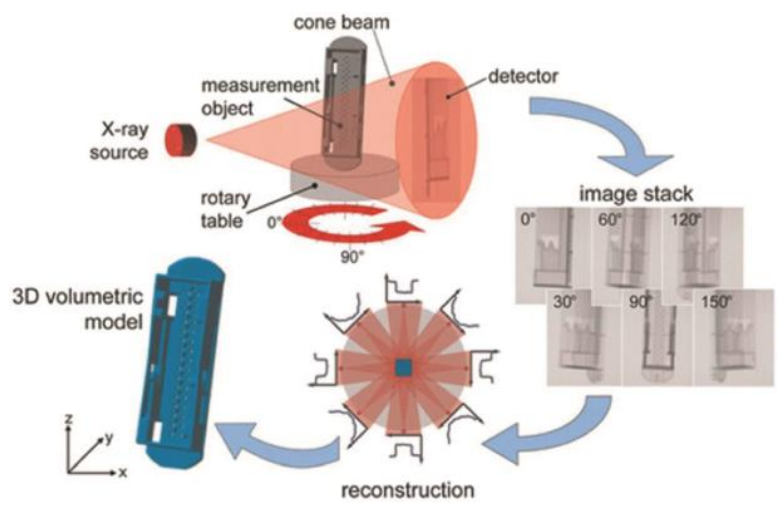

Fig. 6 Basic principle X-ray computed tomography (Weckenmann \& Krämer, 2013).

$\mathrm{XCT}$ is currently the unique technology that can non-destructively measure internal geometrical features (Leach et al., 2019). It does not have any constraints with respect of the measurement of geometric features. Unlike optical technique, XCT is not limited by line-of-sight considerations, and the measured results can be compared with the CAD model to generate a dimensional deviation map (Sun et al., 2012). XCT is particularly suitable for measuring AM components with complex geometry, such as cell scaffolds (Lou et al., 2019). Although XCT has many advantages, it has its own downside. A phenomenon known as the averaging effect' is caused by the partial volume effect (PVE) of the XCT system. This refers to the blurring/fuzziness of the $3 \mathrm{D}$ image that is introduced by the finite spatial resolution of the XCT imaging system and image sampling, which consequently results in the eventual surface morphology becoming blurred (Soret et al., 2007), (Lou et al., 2019) \& (Gasser \& Willnecker, 2019), as shown in Figure 7.

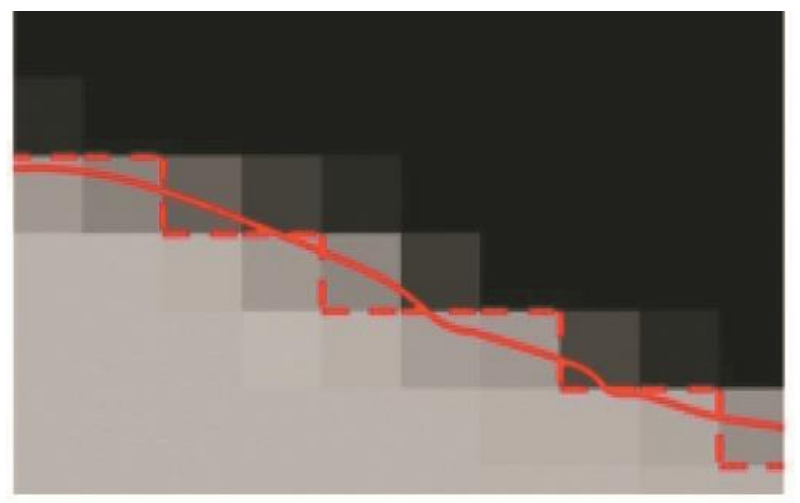

Fig. 7 PVE for measurement surface, the red lines are the surface profile which is obtained (measured) from the object surface (Carmignato \& Savio, 2011). 


\section{Filter and surface parameter (ISO 25178)}

Normally, surface texture is considered as a combination of different wavelength/frequency components. As shown in Figure 8, a measured surface contains multiple different frequency bands, i.e. roughness, waviness and form error. Surface texture analysis aims to extract the roughness and waviness components through the use of filtration techniques. The Gaussian filter is currently the standard filtration technique, which can effectively separate the roughness and waviness band. The roughness component is often the object of interest and is used to compute surface texture parameters (Jiang, 2003.).

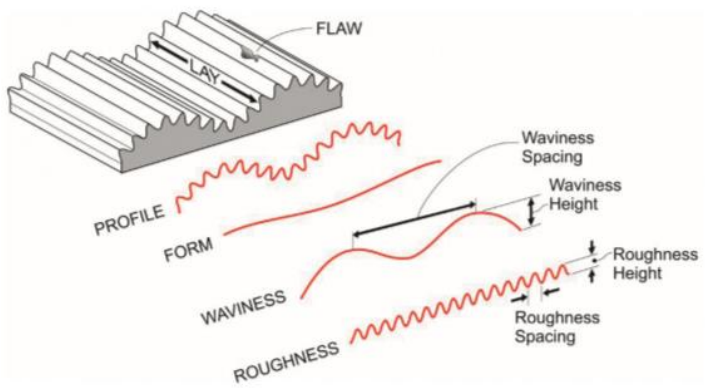

Fig. 8 Decomposed components of a profile (Zygo, 2018).

Sa (Arithmetical average of the surface) and Sq (Root-mean-square deviation of the surface) are the two most frequently used surface texture parameters from ISO $25178-2$, which can reflect the average roughness level of a measured surface (ISO 25178-2:2012) \& (Keyence, n.d.), as per Figure 9.
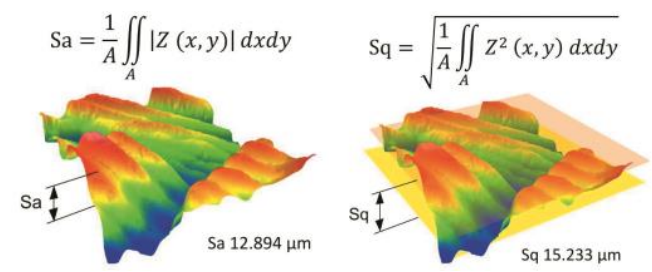

Fig. 9 Formula and $3 \mathrm{D}$ explanatory diagram of $\mathrm{Sa}$ and Sq (Zygo, 2018).

\section{Selection of cut-off wavelengths.}

To use filtration techniques to separate different wavelength components, various cut-off wavelengths need to be specified. $\lambda f$, also known as Form Remove (F-operation), is used to remove surface form . $\lambda c$ (L-filter) removes the larger lateral scale of the surface to form a primary surface or S-F surface, while $\lambda_{\mathrm{s}}$ (S-filter) removes the small-scale lateral scale of the surface (secondary noise). As shown in Figure 10, the SL surface data can be obtained by applying both S-filter and L-filter, thus allowing for the roughness parameters to be calculated (Zygo, 2018).

The selection of $\lambda \mathrm{c}$ and $\lambda \mathrm{s}$ have great impacts on the resulting roughness parameters. A series of $\lambda c$ and $\lambda \mathrm{s}$ are recommended by ISO 4288 . The value of $\lambda \mathrm{c}$ should be set at about 5 times the distance between peaks and valleys (Taylor Hobson, 2002) \& (ISO 4288:1998). The $\lambda$ s parameter is at least 3 times the sample distance (Townsend et al., 2017) \& (Taylor Hobson, 2002). The ISO standards were mainly designed for traditional machined surfaces. (Lou et al., 2019) summarized the choice of cut-off

wavelengths in the existing literature, as shown is table 1 . It has been reported that not all people

Table. 1

Choice of cut-off wavelengths.

\begin{tabular}{|c|c|c|c|c|}
\hline Publication & Measurement size $(\mathrm{mm})$ & $\lambda \mathbf{c}(\mathrm{mm})$ & $\lambda \mathbf{s}(\mu \mathrm{m})$ & $\mathbf{R a} / \mathbf{S a}(\mu \mathrm{m})$ \\
\hline \multirow{2}{*}{ (Triantaphyllou et al., 2015) } & PGI: 40 & 8 & 8 & 13 \\
\hline & Alicona: $2.5 \times 2.5$ & 2.5 & 8 & - \\
\hline (Townsend et al., 2016) & $8 \times 8$ & 8 & 25 & 30.3 \\
\hline (Lou et al., 2019) & $4.7 \times 5.18$ & 0.25 & - & 3.91 \\
\hline (Grimm et al., 2015) & Confocal: $5.4 \times 5.4$ & 0.8 & - & 15 \\
\hline (Fox et al., 2016) & Interferometer: 5.6 & 0.8 & 25 & 26 \\
\hline (Vetterli et al., 2014) & $\begin{array}{l}\text { Profilometry: } 5.6 \\
\text { Leica: } 3.41 \times 2.53 \\
\text { Gelsight: } 8.4 \times 8.4 \\
\text { Keyence }\end{array}$ & $\begin{array}{l}0.8,1.1 \\
- \\
1.1 \\
2\end{array}$ & - & $\begin{array}{l}\sim 10 \\
\sim 13 \\
\sim 14\end{array}$ \\
\hline (Newton et al., 2019) & $\begin{array}{l}\text { Profilometry } \\
\text { Alicona: } 0.8 \times 0.8\end{array}$ & $\begin{array}{l}2.5 \\
-\end{array}$ & $\begin{array}{l}2.5 \\
-\end{array}$ & Ra: 15.8 \\
\hline (Thompson et al., 2017) & Alicona: $3.7 \times 3.7$ & 0.8 & 6.29 & 27 \\
\hline (Cabanettes et al., 2018) & $\begin{array}{l}\text { Profilometry } \\
\text { Alicona: } 3.2 \times 1.9\end{array}$ & $\begin{array}{l}0.25 \\
- \\
\end{array}$ & - & $\begin{array}{l}5.48 \\
19.2 \\
\end{array}$ \\
\hline
\end{tabular}


follow the ISO 4288 standard as a consequence of doubts over the extent to which they are suitable for AM surface texture analysis in their current form. In addition, current research on waviness is very little. The study of waviness is necessary to determine the cut-off wavelength (Lou et al., 2019).

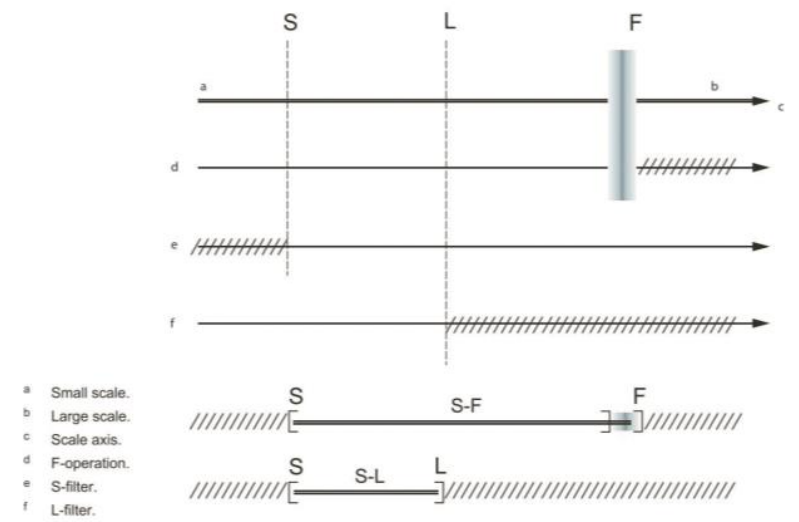

Fig. 10 Relationships between the S-filter, L-filter, F-operation and S-F and S-L surfaces (ISO 251782:2012).

\section{Optical measurement}

\section{Experimental sample}

The sample (a cube) fabricated using the Renishaw AM250 Selective Laser Melting machine using Ti$6 \mathrm{Al}-4 \mathrm{~V}$ powder. The dimension of each edge is 3 $\mathrm{mm}$ - a small size to facilitate XCT scanning. This is shown in Figure 11.
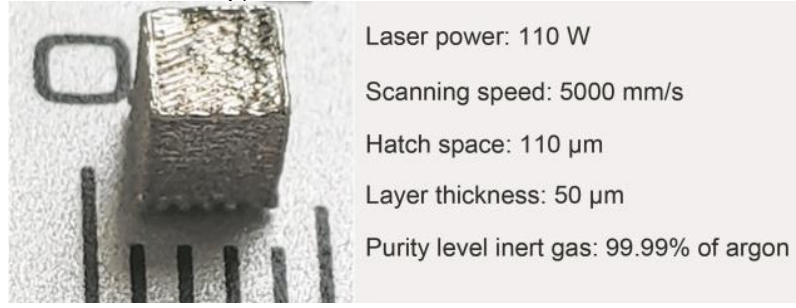

Fig. 11 Experiment sample and build parameter.

\section{Experimental design}

The FVM experiments are carried out by imitating the method described in the reference (Newton et al., 2019), using the control variable method (fixing a certain parameter while changing others). The design uses different lateral resolution, vertical resolution, illumination type, and magnification. The specific configuration parameters are shown in table 2 and Figure 12.
Table. 2

Measurement Parameter setting of Alicona G4.

\begin{tabular}{c|ccc}
\hline Magnification & $\mathbf{1 0 \times}$ & $\mathbf{2 0 \times}$ & $\mathbf{5 0 \times}$ \\
\hline $\begin{array}{c}\text { Illumination } \\
\text { type } \\
\begin{array}{c}\text { Lateral } \\
\text { resolution } / \boldsymbol{\mu m} \\
\text { Vertical }\end{array}\end{array}$ & Coaxial & $\begin{array}{c}\text { Ring light, Coaxial, } \\
\text { Ring light + Coaxial. }\end{array}$ & Ring light \\
resolution $/ \boldsymbol{\mu m}$ & 0.1 & $1,2,5$ & 1 \\
\hline A reference & $0.1,0.5,1$ & 0.1 \\
\hline
\end{tabular}

A reference configuration parameter set is as follows: Magnification 20×, Lateral resolution 2 $\mu \mathrm{m}$, Vertical resolution: $0.1 \mu \mathrm{m}$, Illumination type ring light. Other configuration parameter changes are pivoting in this experiment, around this parameter. See Figure 12. This strategy eventually results in 9 groups of different combinations of configuration parameters.

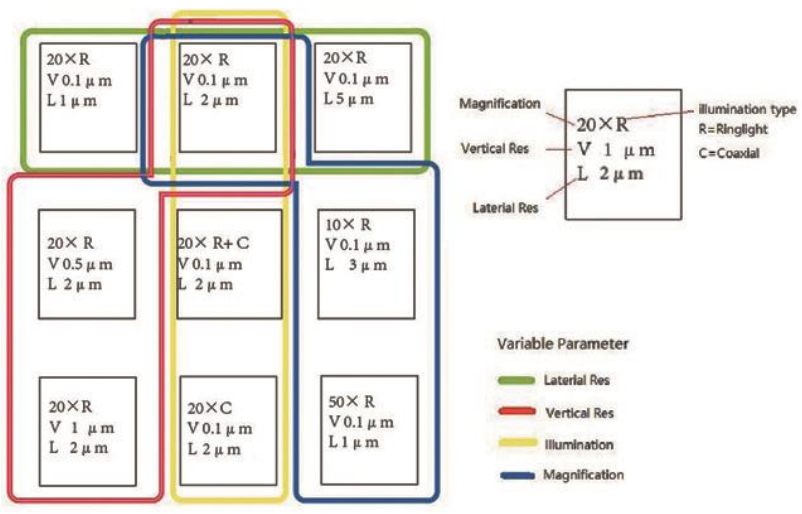

Fig. 12 Correlation diagram of optical measurement parameters.

\section{Optical Measurement Results}

All the measurement results are grouped according to Figure 12 and four sets of data are imported into (MountainsMap Premium 8.0, 2020) respectively. To visually show the differences under different parameters, the data sets are compared by profile comparison and the deviation map generated by surface subtraction.

\section{Magnification}

Different magnifications will lead directly to differences in the capture area. Higher magnifications (e.g. 50x) can capture more surface topography details than smaller magnifications (e.g. $10 \mathrm{x}$ and $20 \mathrm{x}$ ) - see Figure 13. However, smaller magnifications could capture larger areas. For example, the results from $10 \times$ magnification almost reach the edge of the part. 

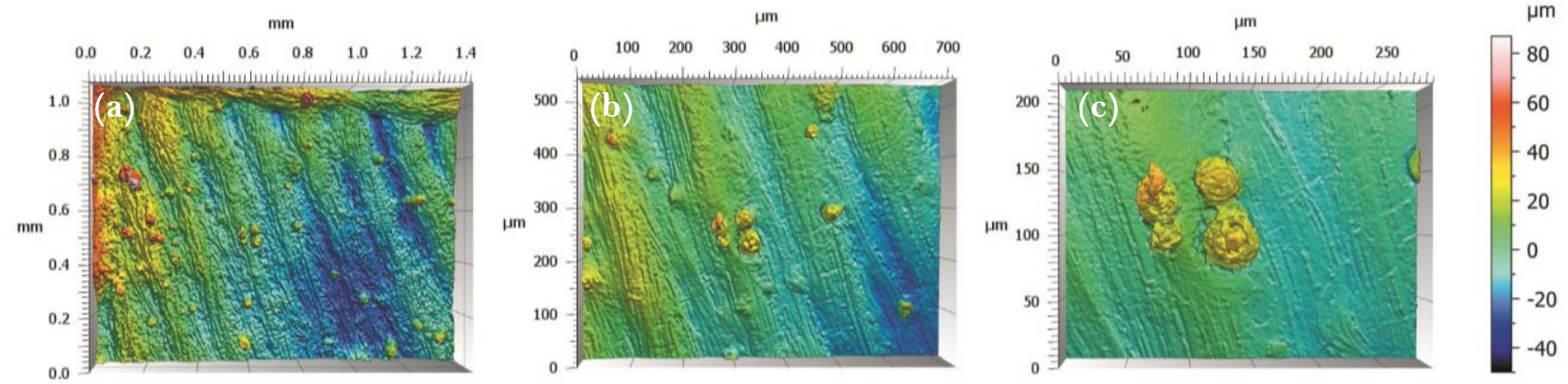

Fig 13. Height map of top surface under ring light illumination: (a) magnification 10×; (b) magnification 20×; (c) magnification 50×.
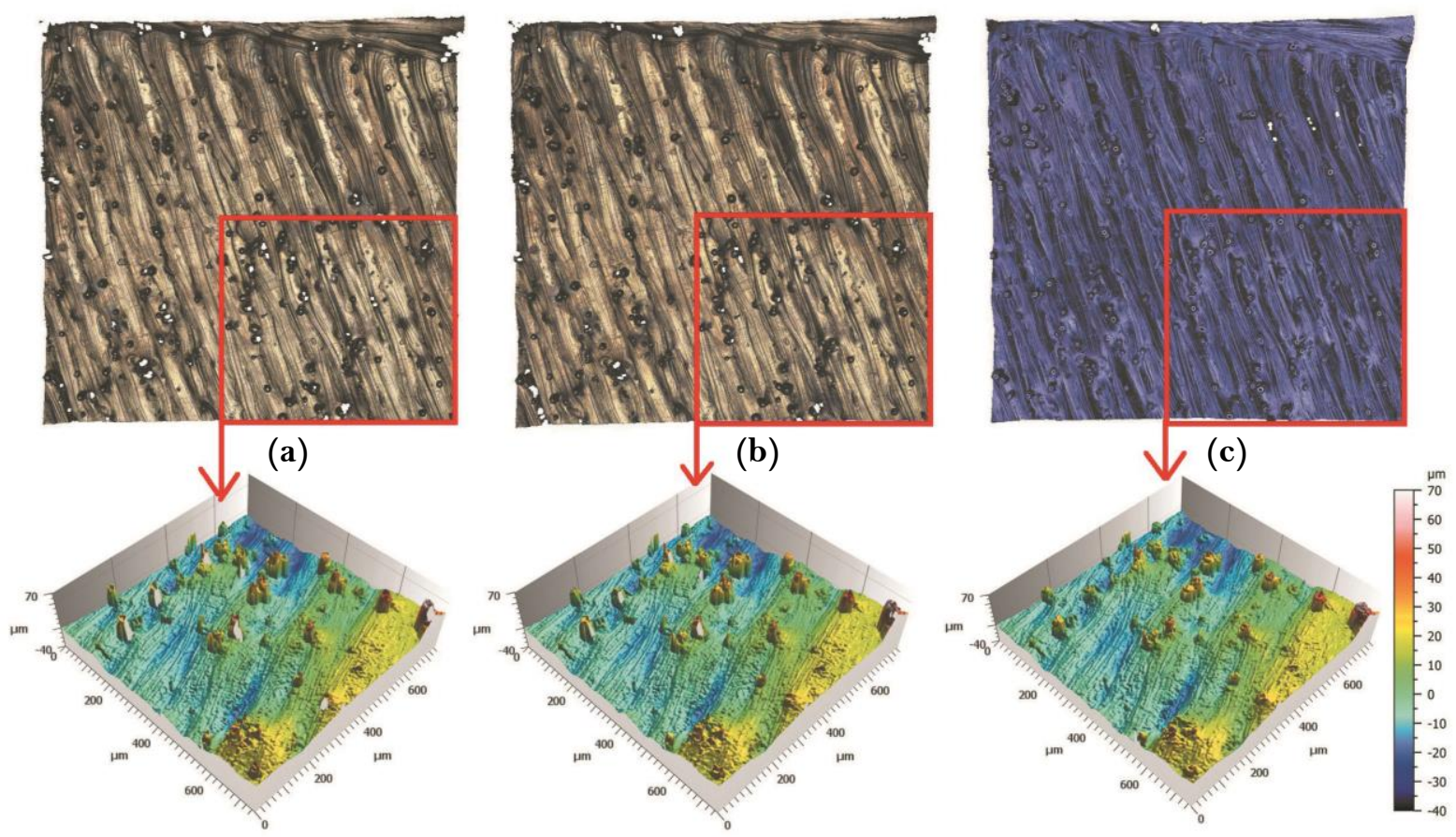

Fig.14 Visual map and zoom height map of top surface under vertical resolution $0.1 \mu \mathrm{m}$, lateral resolution $2 \mu \mathrm{m}$, magnification 20×, (a) Coaxial; (b) Ring light + Coaxial; (c) Ring light.

\section{Illumination type}

It can be seen from Figure 14 that each different illumination type results in different measurement performances. Among them, around the grooves on the surface measured by coaxial light and some dark spots around some particles, the light is not captured by the detector, see Figure 14(a). The surface also presents more overexposure, namely missing points (non-measured points). The surface measured by the combination of coaxial light and ring light is similar to that measured by coaxial light on its own, but the number of non-measured points are reduced - see Figure 14(b) and (c).

NMP is observed in the measured surface with the ring light, because it is able to capture a higher tilt angle (Bruker alicona, n.d.). This in turn means that the topographical features of deeper valleys can be detected. In the profile diagram, the ring light detects the surroundings of all particles and deep valleys, while the coaxial light results in more NMPs. This is due to higher reflection, resulting in the overall exposure being too strong. The outcome is that the use of the coaxial light leads to too much data being lost, and the tip protrusion feature appearing on the top of the particle. The measurement result of the combination of coaxial light and ring light reduces the amount of missing data, while ensuring that the overall visual is almost the same as that of the coaxial light alone. 


\section{Vertical Resolution}

The results of different vertical resolutions are illustrated in Figure 15. There is almost no difference by visual inspection. However, the vertical resolution has a significant impact on the scan time. The finer vertical resolution (small value) will take longer to do the scan.
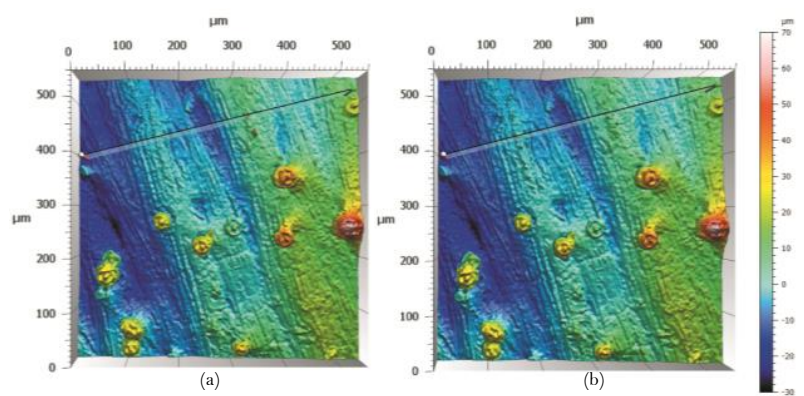

Fig .15 Height map of top surface under lateral resolution $2 \mu \mathrm{m}$, magnification $20 \times$, ring light illumination, (a) vertical resolution $0.1 \mu \mathrm{m}$, (b) vertical resolution $1 \mu \mathrm{m}$.

From the profile comparison, see Figure 16(a), it is found that the effect of different vertical resolutions on surface topography measurement is almost trivial. The comparison only presents a slight difference between the profile peaks and valleys. Figure 16(c) illustrates the subtraction of two surfaces measured with two different vertical resolutions. The subtraction map only displays a relatively obvious height difference around the particles, while the majority of the deviation tends to be zero. Overall, the change in vertical resolution has less impact on the surface topography measurement in comparison to other configuration parameters, and it is almost negligible.

\section{Lateral Resolution}

The lateral resolution, however, presents a significant impact on surface topography measurement - see Figure 17. More details can be captured with finer lateral resolution. The welding ripple (roughness level) and particle adhesion can be clearly seen in Figure 17(a). This characteristic can be useful for the capture of small features. In comparison, the surfaces resulting from courser resolutions are relatively smooth, and only the characteristics of melted tracks and smooth particles can be observed.
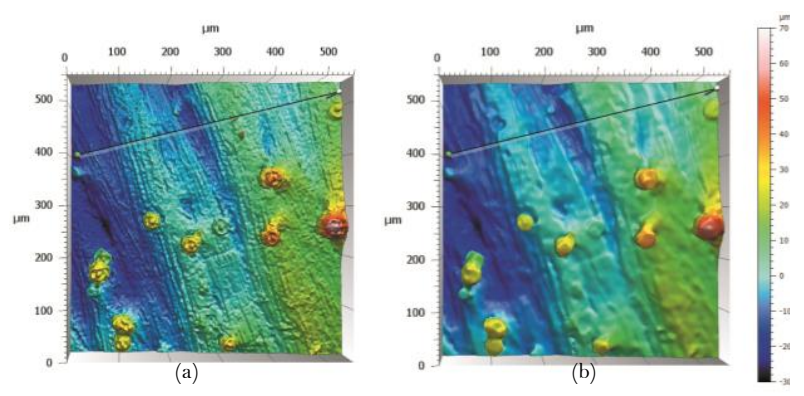

Fig. 17 Height map visualisation of top surface under Vertical Resolution $0.1 \mu \mathrm{m}$, magnification 20×, Ring light type for illumination, (a) Lateral Resolution $2 \mu \mathrm{m}$, (b) Lateral Res $5 \mu \mathrm{m}$.

Figure 16(b) and (d) illustrates the profile comparison and the subtraction map of two lateral resolution. It can be found from the subtraction map that different lateral resolutions have many deviations in details. Using coarser lateral resolution, many fine topographical details are lost. In comparison, finer lateral resolution could capture fine topographical feature. However, around the particles, there are protruding spikes that might be caused by noise or other reasons. It can be seen from the profile that the larger resolution value seems to have a smoothing effect on the terrain.
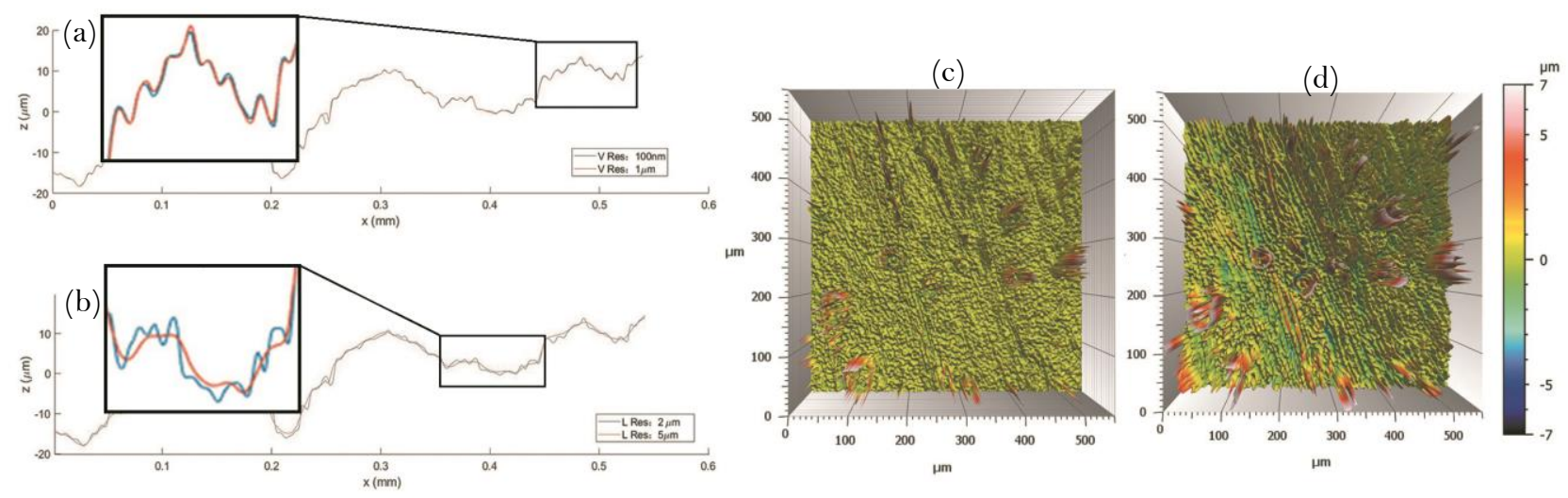

Fig. 16 Comparison of, profile diagram, (a) vertical resolution; (b) lateral resolution. Subtraction surface under (c) vertical resolution $0.1 \mu \mathrm{m}$ subtract $1 \mu \mathrm{m}$; (d) lateral resolution $2 \mu \mathrm{m}$ subtract $5 \mu \mathrm{m}$. 


\section{Selection of $\lambda c$ and $\lambda s$ and Filter}

As mentioned above, the ISO standards are not necessarily applicable to AM surface measurement. However, the purpose of this project is not to obtain the accurate values of surface parameters, but to compare the trend of parameter changes. Therefore, the cut-off wavelength of this report is in accordance with the recommendation of ISO 4288. For the top surface of the AM sample, the edge area is not suitable for surface measurement due to the edge elevation. So only the middle $1.7 \mathrm{~mm} \times 1.7 \mathrm{~mm}$ region is intercepted. According to ISO 4288 standards, the cut-off $\lambda c$ needs to be one-fifth of evaluation length of $1.7 \mathrm{~mm}$, which is equivalent to $0.34 \mathrm{~mm}$. The nearest standard $\lambda c$ value per ISO 4288 is $0.25 \mathrm{~mm}$. Thus $\lambda \mathrm{c}$ was chosen to be $0.25 \mathrm{~mm}$. Regarding $\lambda s$, since the size of the top surface of this measurement result is small, the lowest level of $\lambda \mathrm{s}$ $(2.5 \mu \mathrm{m})$ is selected according to ISO 4288 .

\section{Surface parameters and analyse}

Following surface filtering, the surface texture parameters $\mathrm{Sa}$ and $\mathrm{Sq}$ are calculated. The parameter results are illustrated in Figure 18 and listed in Table 3.

By comparison, it is found that the ring light illumination resulted in fewer NMPs (only half of the time was the amount of data missing considered to be equivalent to the coaxial type), due to it being more capable of capturing deep valley features (match with Figure 14), as well as the surface parameter values being slightly higher than the result of coaxial light. The vertical resolution seems to have little or no effect on surface parameters. However, as the lateral resolution changes (from fine to coarse), the $\mathrm{Sa}, \mathrm{Sq}$ and $\mathrm{NMP}$ values go decrease. In the case of the $1 \mu \mathrm{m}$ lateral resolution, $\mathrm{Sa}$ and $\mathrm{Sq}$ have larger values, and the NMP value is nearly double that of the other results (almost close to coaxial). Therefore, it is found that the lateral resolution and the type of illumination has a significant impact on the surface parameters.

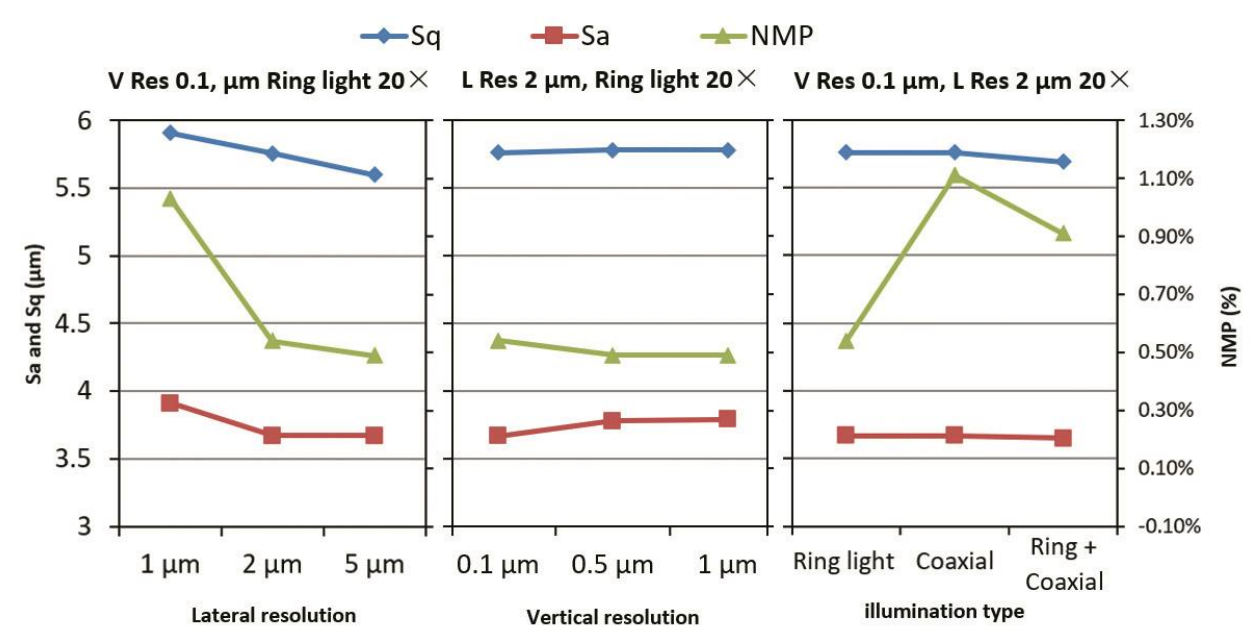

Fig. 18 Trend graph surface parameter.

Table. 3

$\mathrm{Sa}, \mathrm{Sq}$ and NMP for Optical surface (Second Polynomial form removal, $\lambda \mathrm{c} 250 \mu \mathrm{m}, \lambda \mathrm{s} 2.5 \mu \mathrm{m}$ ).

\begin{tabular}{|c|c|c|c|c|c|c|}
\hline \multirow{2}{*}{$\begin{array}{l}\text { Resolution } \\
/ \mu \mathrm{m}\end{array}$} & \multicolumn{3}{|c|}{ V Res 0.1 with Ring light (Variety L Res) } & \multicolumn{3}{|c|}{ L Res 2 with Ring light(Variety L Res) } \\
\hline & L Res 1 & L Res 2 & L Res 5 & V Les 0.1 & V Les 0.5 & V Les \\
\hline $\mathrm{Sq} / \mu \mathrm{m}$ & 5.91 & 5.76 & 5.6 & 5.76 & 5.78 & 5.78 \\
\hline $\mathrm{Sa} / \mu \mathrm{m}$ & 3.91 & 3.67 & 3.67 & 3.67 & 3.78 & 3.79 \\
\hline NMP & $1.03 \%$ & $0.54 \%$ & $0.49 \%$ & $0.54 \%$ & $0.49 \%$ & $0.49 \%$ \\
\hline \multirow{2}{*}{$\begin{array}{l}\text { Resolution } \\
/ \mu \mathrm{m}\end{array}$} & \multicolumn{6}{|c|}{ V Res 0.1 L Res 2 (Variety Type of illumination) } \\
\hline & \multicolumn{2}{|l|}{ Ringlight } & \multicolumn{2}{|l|}{ Coaxial } & \multicolumn{2}{|c|}{ Coaxial+Ring } \\
\hline $\mathrm{Sq} / \mu \mathrm{m}$ & \multicolumn{2}{|l|}{5.76} & \multicolumn{2}{|l|}{5.76} & \multicolumn{2}{|l|}{5.69} \\
\hline $\mathrm{Sa} / \mu \mathrm{m}$ & \multicolumn{2}{|l|}{3.67} & \multicolumn{2}{|l|}{3.67} & \multicolumn{2}{|l|}{3.65} \\
\hline NMP & \multicolumn{2}{|l|}{$0.54 \%$} & \multicolumn{2}{|l|}{$1.11 \%$} & \multicolumn{2}{|l|}{$0.91 \%$} \\
\hline
\end{tabular}




\section{XCT Measurement}

\section{XCT scanning set-up}

Fix the experimental sample on the plastic bracket, as shown in Figure 19. The remaining residual radiation passes through the sample and is captured by the detector. The density of the plastic is much lower than the sample, and the radiation will have little attenuation when passing through the plastic.
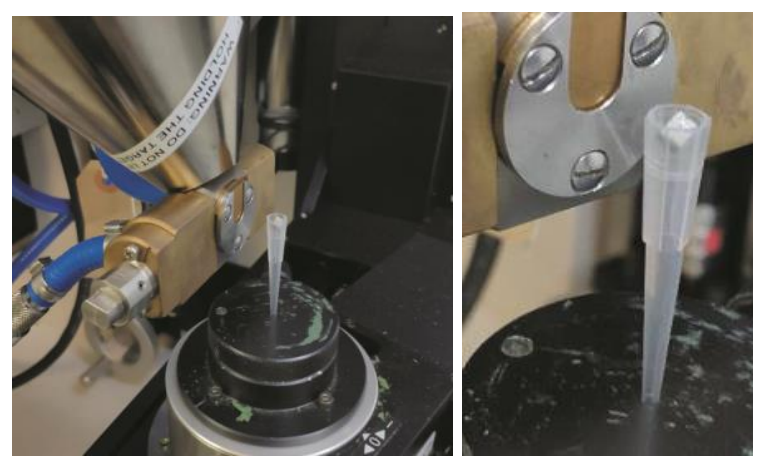

Fig. 19 Use plastic to lift sample and fix it in XCT.

Adjust the rocker to make the image fill the screen as much as possible in order to ensure a larger magnification, as shown in Figure 20(a). Set the measurement parameters, power, voltage, exposure time, gain, filter and other parameters according to Table 4. The computer shows that the current Voxel size is equal $6 \mu \mathrm{m}$, and that a total of 1583 projections were captured in the whole process.
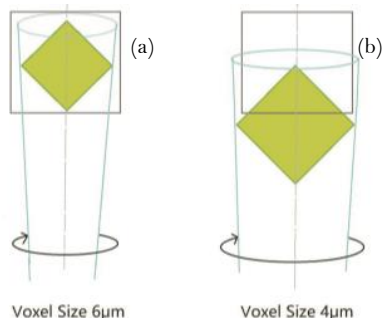

Fig. 20 The sample image on detectors, (a) voxel size $6 \mu \mathrm{m}$, (b) voxel size $4 \mu \mathrm{m}$.

Table. 4

Measurement parameter for XCT.

\begin{tabular}{l|l}
\hline $\begin{array}{l}\text { XCT scanning } \\
\text { parameters }\end{array}$ & Values \\
\hline Voltage & $120 \mathrm{kV}$ \\
Power & $9 \mathrm{~W}$ \\
Exposure & $1000 \mathrm{~ms}$ \\
Gain & $12 \mathrm{~dB}$ \\
Filter Thickness & $0 \mathrm{~mm}$ (No Filter) \\
Frames Per Project & 2 \\
Projections Number & 1583 \\
Detector size(pixels) & $1008 \times 1008$ \\
\hline
\end{tabular}

In the Optical measurement section, Sa of FVM is less than $6 \mu \mathrm{m}$, but the minimum voxel size available to cover the whole sample is $6 \mu \mathrm{m}$. As suggested by (Townsend et al., 2018), voxel size needs to be at least half of the Sa value, so the voxel size needs to be further reduced. This forces us to reduce the area of interest for scanning and in turn leads to the scan needing to over cover the top corner of the sample, with the rest of the sample out of scope. To enable this, we have to ensure that the top corner has a complete image for all 360 degrees (the only changes that can be made are to the magnification and the distance of detector), as shown in Figure 2O(b) and 21. The same XCT configuration is used, only reducing the voxel size to $4 \mu \mathrm{m}$, which is the smallest voxel size that the employed XCT can achieve.

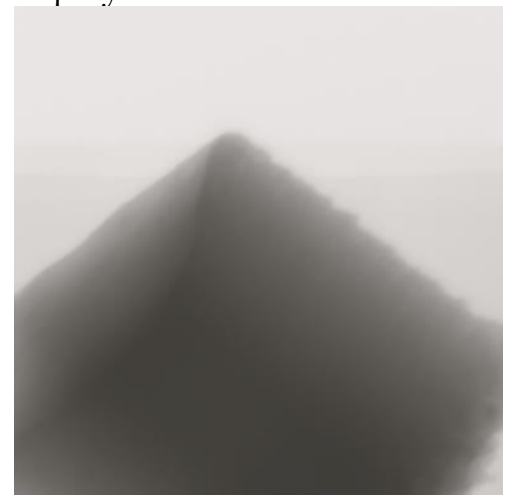

Fig. 21 Projection sketch of voxel size $4 \mu \mathrm{m}$.

\section{Data processing}

$3 \mathrm{D}$ volume data is reconstructed using (CT Pro $3 \mathrm{D}$, n.d.) and imported into (VGStudio Max, 3.0) for further analysis. The local iterative surface determination is used with the initial profile resulting from an automatic configuration. The surface data is then exported in the form of stereolithography (STL) files. The mesh generation is set to the highest precision level to ensure that the surface details are lost due mesh data dissemination.

In addition, the result of the voxel size being $4 \mu \mathrm{m}$ is analysed using three other different surface determination methods, with the aim of investigating their impacts on surface texture evaluation. These surface determination methods require various combinations of local iterative searching, ISO 50, automatic and manual identification of material and background, eventually resulting into three types, i.e. Local iterative, Automatic + ISO 50\%, Manual + ISO $50 \%$. A total of six STL file were obtained.

Mesh surfaces are imported into CloudCompare v2.11.0, and re-oriented to align with the $Z$ positive 
direction. Because the two sets of data $(4 \mu \mathrm{m}$ and 6 $\mu \mathrm{m})$ are two separate measurements, the result is that their coordinates are different, as shown in Figure 22. Surface registration is then performed to enable the overlap of common areas, followed by the comparison of overlapping surface topography.

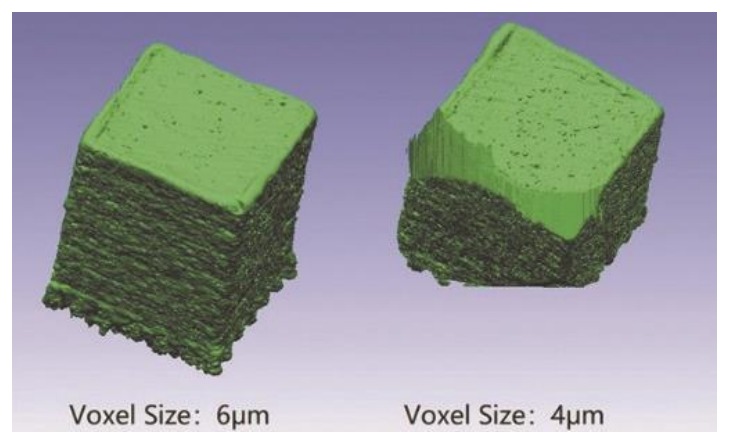

Fig. 22 Result of different voxel size.

\section{XCT Result}

\section{Voxel Size}
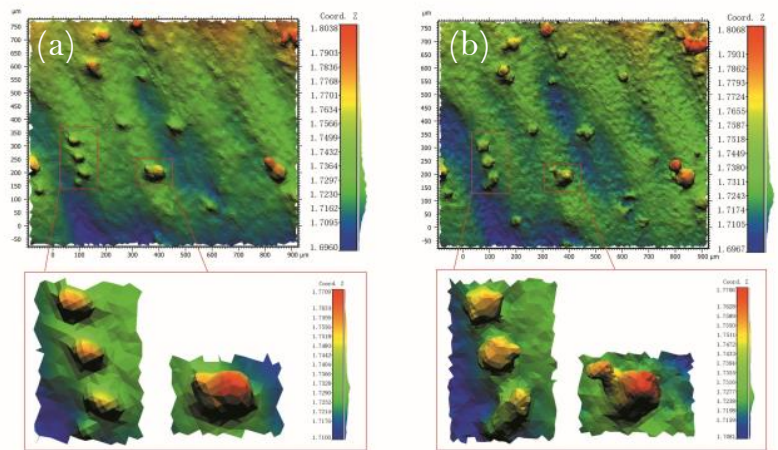

Fig. 23 STL visual rendering $\operatorname{map}(3 \mathrm{D})$, (a) voxel size $6 \mu \mathrm{m}$, (b) voxel size $4 \mu \mathrm{m}$.

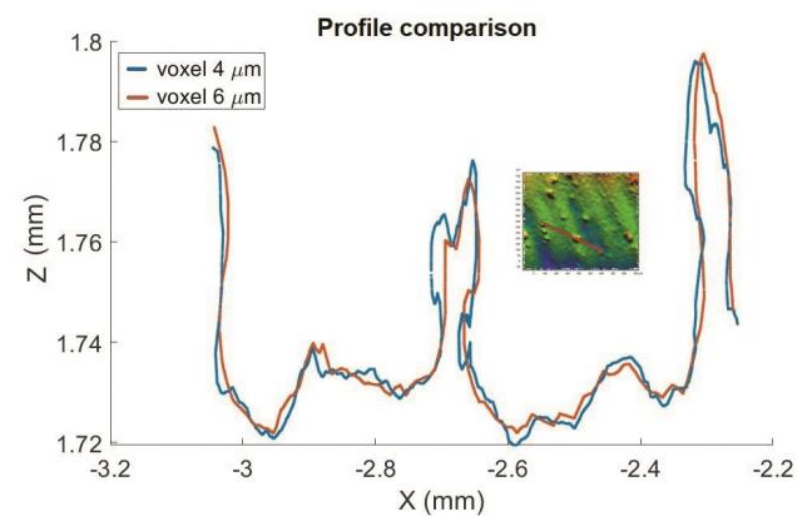

Fig. 24 Profile diagram of voxel size $4 \mu \mathrm{m}$ and voxel size $6 \mu \mathrm{m}$.
The comparison of measurement results of $4 \mu \mathrm{m}$ and $6 \mu \mathrm{m}$ is done by visually inspecting the surface height map (see Figure 23) as well as the profile comparison via (MATLAB, 2020a) (Figure 24). It can be found that the finer voxel size (smaller value) has a larger number of meshes and also more surface details, as shown in Figure 23. On the contrary, the larger voxel shows the more blurred surface. On the surface topography of $4 \mu \mathrm{m}$ voxel size, the details on the top and surrounding area of the visible particles are displayed. In comparison, the mesh surface of the $6 \mu \mathrm{m}$ variant is less dense. We have found that some particles were not captured, as it was almost impossible to distinguish their features. The profile also shows that the attached particle feature is missing, as presented in Figure 24. In addition, the profile also shows that the finer the voxel size, the rougher the surface profile is, and vice versa.

\section{Surface determination}
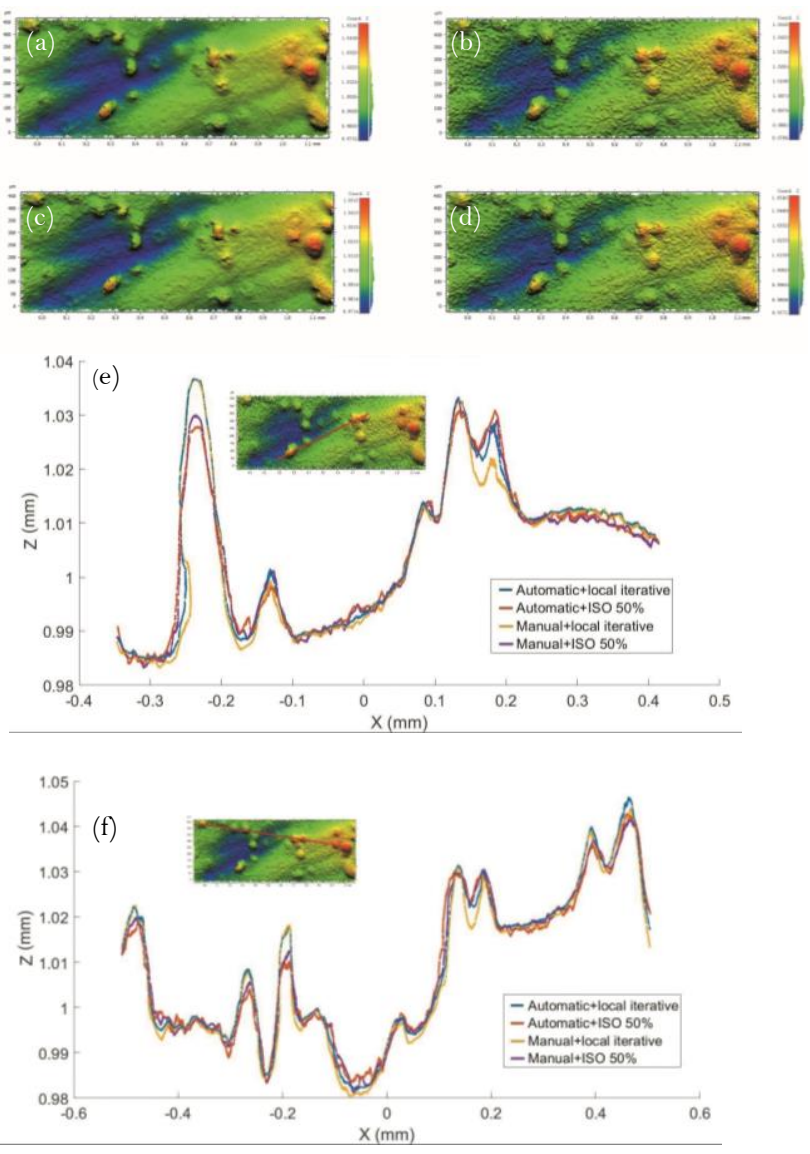

Fig. 25 STL visual rendering $\operatorname{map}(3 \mathrm{D})$ under (a) Automatic + local iterative, (b) Automatic + ISO 50, (c) Manual + local iterative, (d) Manual + ISO50, and under the profile of in two places, (e) and (f). 
By comparing the height maps resulting from various surface determination methods, as shown in Figure 25(a-d), it can be found that the results of the manual selection background and automatic selection are almost the same, but the local iterative and ISO 50 algorithms showed the differences. The surface generated by the ISO 50 method seems to be rougher, even on and around the particles. Many noise-like features are observed. On the other hand, the result of the local iterative algorithm looks smoother. As shown in Figure 25(e), observing the profile map, it can be found that the local iterative surface determination can restore the re-entrant feature better than ISO 50, and the captured particles are mostly higher than those of ISO 50.

\section{Surface texture parameters}

XCT measurement data is derived from mesh surfaces and they are then imported into MountainsMap Premium 8.o. The surface filtration configuration of XCT is similar to FVM. In order to facilitate the comparison, the choice of cut-off wavelength is consistent with FVM.
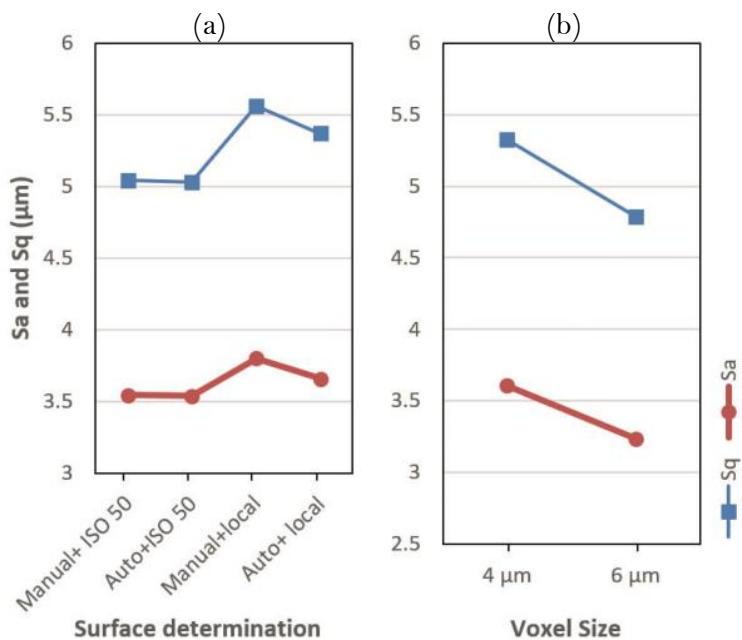

Fig. 26 Surface parameter variation in response to (a) surface determination methods, (b) voxel size.

Figure 26 illustrates the response of $\mathrm{Sa}$ and $\mathrm{Sq}$ values to various voxel sizes and surface determination methods. For different voxel sizes (magnifications), the values of $\mathrm{Sa}$ and $\mathrm{Sq}$ decrease with the increase in voxel size. This is because fine details cannot be captured by voxel size $6 \mu \mathrm{m}$. Regarding the different surface determination results, manual selection and automatic selection did not show significant impact, but the local iterative algorithm resulted in higher parameter values than ISO 50 because its captured particleswere higher.

\section{Comparison of FVM and XCT Measurements}

\section{Data selection and preparation}

We extracted the reference results obtained by the two instruments for comparison; optical use ring light type with $0.1 \mu \mathrm{m}$ and $1 \mu \mathrm{m}$ vertical and lateral resolution respectively, and XCT using $4 \mu \mathrm{m}$ voxel size with automatic plus local iterative surface determination. In order to compare the specific differences between FVM and XCT, additional side surfaces are added for comparison. The parameters used were as described earlier in the report. Therefore, a total of four data sets are compared, including the top and side surface measured by FVM, and the top and side surface measured by $\mathrm{XCT}$.

FVM measurement data sets are converted into point clouds and then imported into CloudCompare to enable the comparison with the XCT measurement. The alignment method and parameters are almost the same as used in the XCT magnification comparison. The only difference is that the side surface is added to participate in the alignment, and the result of both the adjusted nonadjusted scales are obtained respectively. Due to the fact that XCT will produce size errors during the surface determinant process (Townsend et al., 2017), the scaling can obtain and observe the size of measurement result.

\section{Top surface comparison}

As shown in Figure 27, it is found that while FVM can capture more details, welding stripes are clearly visible. In comparison, XCT only captures the larger horizontal size of the ripples and hardly captures any roughness in texture. However, the optical results have inevitable data loss surrounding the particles and exposure in smooth areas, while the XCT can capture all the data (no data missing). Comparing their profile (see Figure 28) shows that the characteristics of re-entrant can be captured by XCT, but FVM's result displays a vertical flank due to the FVM measurement principle. In addition, no matter whether the data is taken from the profile or the height map, it is found that the adjusted scale has minimal effect on the surface texture. 


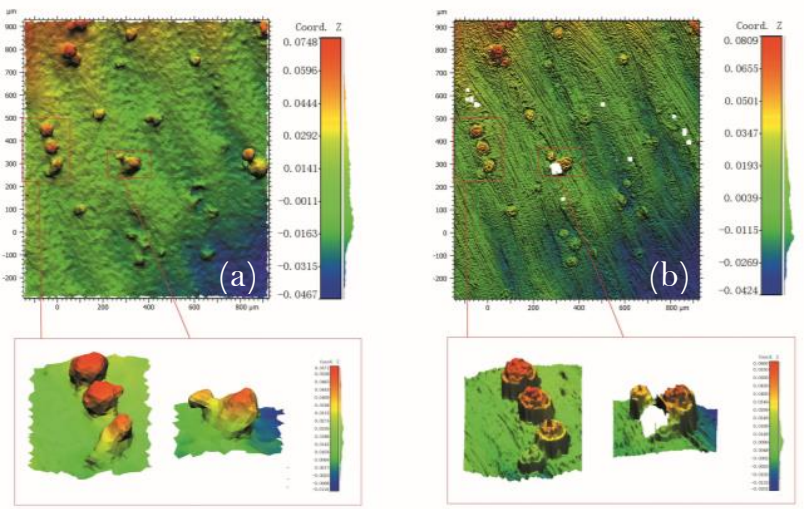

Fig. 27 Height map of top surface under: (a) XCT which is voxel size $4 \mu \mathrm{m}$, automatic + local surface determination; (b) FVM which is lateral resolution $1 \mu \mathrm{m}$, magnification $20 \times$, ring light illumination, vertical resolution $0.1 \mu \mathrm{m}$.

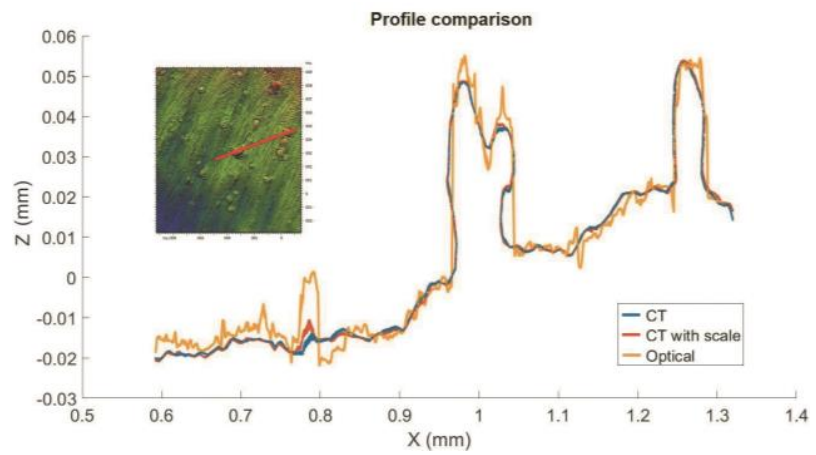

Fig. 28 Profile diagram under FVM and XCT on top surface.

\section{Side surface comparison}

With respect of the side surface, we have found that although it is possible to capture internal structural and re-entrant features with XCT, the limitations of the partial volume effect result in features which are too 'fine' being filtered out, as shown in Figure 29 and 30. Other than the side surface however, there is no NMP in the XCT measurement - a result which would be almost impossible with FVM. The NMP value of the side surface of FVM in this case is as high as $4.79 \%$. There are a lot of spherical protruding particles on the side of the AM metal parts, as Figure 29 shows. The profile comparison of spherical features in Figure 30 indicates that FVM's result is sharper and shows more microscale features than that of XCT.
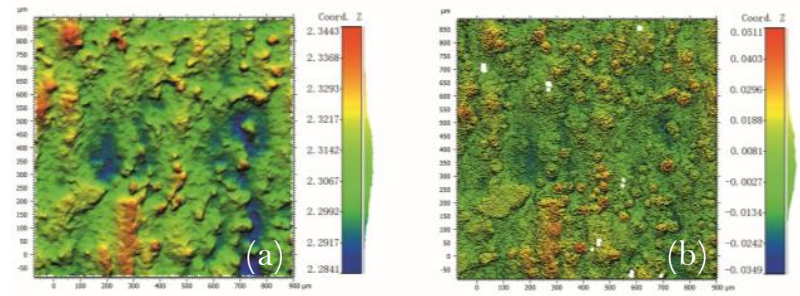

Fig. 29 Height map of top surface under: (a) XCT which is voxel size 3, automatic + local surface determination; (b) FVM which has a lateral resolution of $1 \mu \mathrm{m}$, magnification $20 \times$, ring light illumination vertical resolution $0.1 \mu \mathrm{m}$.

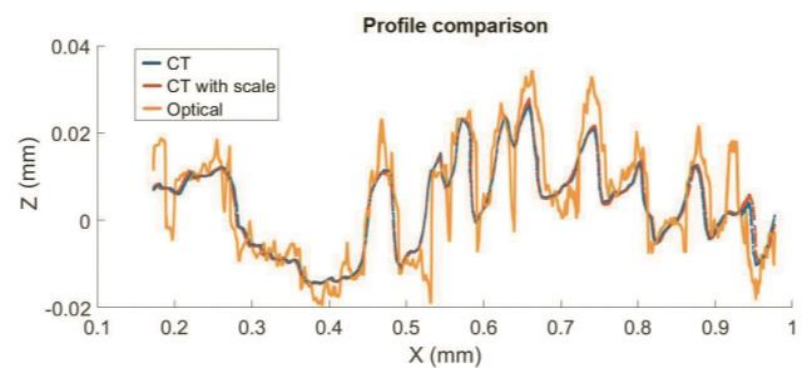

Fig. 30 Profile comparison of side surface taken from FVM and XCT measurement of side surface.

Surface parameter comparison of FVM and XCT Comparing the results of surface parameters, it is evident that the Sa and Sq of FVM are higher than those of XCT in all cases, as shown in Figure 31. This difference is even more significant in the case of side surfaces. In (Townsend et al., 2017), the optical results deviate from the XCT results by less than $2.5 \%$. One possible reason for this could be that the surface roughness of the sample used in this experiment is much smaller, and the voxel size of XCT cannot be reduced to be less than half of the optically measured Sa value.

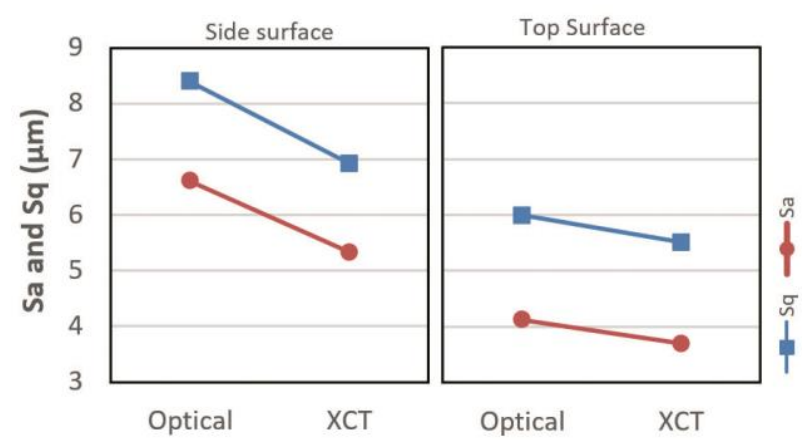

Fig. 31 Surface parameter comparison of FVM and XCT. 


\section{Conclusion}

The influence of the various measurement parameters FVM and XCT on the surface topography of an AM part was investigated. The FVM and XCT results taken at the same position were analysed and the surface topographies of both techniques and their respective derived surface roughness parameters were also compared.

\section{In FVM measurement}

- It was found that the lateral resolution has a significant impact on the measurement results. Selecting the appropriate lateral resolution depends on the scale of features that the enduser is interested in.

- On the contrary, the vertical resolution only has a trivial effect on measurement results. Setting too fine a vertical resolution will greatly increase the measurement time.

- The ring light illumination, in comparison with other illumination types, can be helpful in reducing the number of NMP.

\section{In XCT measurement}

- Although a smaller voxel size can get more details on the surface texture, it can also restrict the size of detection, not being able to cover the sample completely.

- The local iterative surface determination works better than ISO 50 in resolving the details of surface texture. Meanwhile, automatic selection of materials does not make much difference compared to manual selection.

\section{Comparison of FVM and XCT}

- Optical measurements usually exhibit finer resolution than XCT, resulting in more surface details.

- XCT can capture the shortcomings of optical measurement such as re-entrant features and has no NMPs.

FVM and XCT can be adapted for many AM fabricated industrial applications. For example, medical implants like artificial knee and femur joints, and lattice structured porous bone scaffolds. Aerospace engine applications are also present, including temperature controllers, internal cooling channels of a heat exchanger and so on (Townsend et al., 2016). Based on their respective advantages and disadvantages, the choice of FVM and XCT depends on what kind of result the operator/reader wants to get.

Future work will investigate the results of other surface parameters between XCT and FVM, such as the functional volume parameters, and the study of the relationship between sample distance and voxel size under the corresponding results. More work could also be done around further comparisons based on varying Voxel size results for XCT. A deficiency of the current work is the lack of repeated measurements, and as such it is recommended that further studies build on these results with this in mind.

\section{Acknowledgements}

The author would like to thank Dr Shan Lou (supervisor) for his proof-reading, support and guidance, and Dr Wenhan Zeng for guidance. also, thanks for PhD student Xiao Chen for assistance and training on the data processing, and $\mathrm{PhD}$ student Shubhavardhan Ramdurga Narasimharaju producing the experiment sample and grammar suggestions.

\section{$\underline{\text { References }}$}

Additive manufacturing. (2019). GE Announces Additive Manufacturing Breakthrough in Commercial Aviation Retrieved from https://www.additivemanufacturing.media/n ews/ge-announces-additive-manufacturingbreakthrough-in-commercial-aviation

Bruker alicina. (n.d.). focus - variation the technical principle. Retrieved from https://www.alicona.com/en-uk/ourtechnology/focus-variation/

Cabanettes, F., Joubert, A., Chardon, G., Dumas, V., Rech, J., Grosjean, C., \& Dimkovski, Z. (2018). Topography of as built surfaces generated in metal additive manufacturing: A multi scale analysis from form to roughness.

Precision Engineering, 52(January), 249-265. https://doi.org/10.1016/j.precisioneng.2018. 01.002

Carmignato, S., \& Savio, E. (2011). Traceable volume measurements using coordinate measuring systems. CIRP Annals Manufacturing Technology, 60(1), 519-522. https://doi.org/10.1016/j.cirp.2011.03.061

Digital Surf Mountains ${ }^{\circledR}$ surface imaging \& metrology software. (2020). MountainsMap Premium 8.0 http://www.digitalsurf.com/en/mntkey.html

Fox, J. C., Moylan, S. P., \& Lane, B. M. (2016). Preliminary study toward surface texture as a process signature in laser powder bed fusion additive manufacturing. Proceedings ASPE/Euspen 2016 Summer Topical Meeting: Dimensional Accuracy and Surface Finish in Additive Manufacturing, September, 168-173.

GPL software. (2020). CloudCompare v2.11.0 https://www.danielgm.net/cc/

Grimm, T., Wiora, G., \& Witt, G. (2015). Characterization of typical surface effects in additive manufacturing with confocal 
microscopy. Surface Topography: Metrology and Properties, 3(1).

https://doi.org/10.1088/2051$672 \mathrm{X} / 3 / 1 / 014001$

Hiersemenzel, F. (2019). Development towards a focus variation based micro-co-ordinate measuring machine. Retrieved from https://repository.lboro.ac.uk/articles/Devel opment_towards_a_focus_variation_based_m icro-co-

ordinate_measuring_machine/9530021

ISO 25178-2. (2012). Geometrical product specifications (GPS)- Surface texture: Areal. Terms, definitions and surface texture parameters. BSI Standards Publication.

ISO 4288. (1996). Geometrical Product Specifications (GPS)- Surface texture: Profile method-Rules and procedures for the assessment of surface texture. BSI Standards Publication.

J.Gasser, \& J, W. (2019). Bone Measurements by Peripheral Quantitative Computed. 49(10), 2956-2963. 10.1007/978-1-4939-8997-3_29.

Jiang, X. (2003). Multi-scalar Filtration Methodologies. 5. Advanced Techniques for Assessment Surface Topography https://doi.org/10.1016/B978-1903996119/50005-0

Keyence. (n.d.). Area Roughness Parameters

Retrieved from

https://www.keyence.com/ss/products/micr oscope/roughness/surface/parameters.jsp

Leach, R. K., Bourell, D., Carmignato, S., Donmez, A., Senin, N., \& Dewulf, W. (2019).

Geometrical metrology for metal additive manufacturing. CIRP Annals, 68(2), 677-700. https://doi.org/10.1016/j.cirp.2019.05.004

Lou, S., Brown, S. B., Sun, W., Zeng, W., Jiang, X., \& Scott, P. J. (2019). An investigation of the mechanical filtering effect of tactile CMM in the measurement of additively manufactured parts. Measurement: Journal of the International Measurement Confederation, 144, 173-182. https://doi.org/10.1016/j.measurement.2019 .04 .066

Lou, S., Jiang, X., Sun, W., Zeng, W., Pagani, L., \& Scott, P. J. (2019). Characterisation methods for powder bed fusion processed surface topography. Precision Engineering, 57, 1-15. https://doi.org/10.1016/j.precisioneng.2018. 09.007

Lou, S, Pagani, L., Zeng, W., Ghori, M. U., Jiang, X., \& Scott, P. J. (2019). Surface texture evaluation of additively manufactured metallic cellular scaffolds for acetabular implants using X-ray computed tomography. Bio-Design and Manufacturing, 2(2), 55-64. https://doi.org/10.1007/s42242-019-00042$\mathrm{x}$
Maskery, I., Aremu, A. O., Simonelli, M., Tuck, C., Wildman, R. D., Ashcroft, I. A., \& Hague, R. J. M. (2015). Mechanical Properties of Ti6Al-4V Selectively Laser Melted Parts with Body-Centred-Cubic Lattices of Varying cell size. Experimental Mechanics, 55(7), 12611272. https://doi.org/10.1007/s11340-015002 1-5

MathWorks. (2020). MATLAB 2020a. Retrieved from https://uk.mathworks.com/ products/matlab.html.

Mehrpouya, M., Dehghanghadikolaei, A., Fotovvati, B., Vosooghnia, A., Emamian, S. S., \& Gisario, A. (2019). The potential of additive manufacturing in the smart factory industrial 4.0: A review. Applied Sciences, 9(18), 3865. doi:10.3390/app9183865

Newton, L., Senin, N., Gomez, C., Danzl, R., Helmli, F., Blunt, L., \& Leach, R. (2019). Areal topography measurement of metal additive surfaces using focus variation microscopy. Additive Manufacturing, 25, 365389.

https://doi.org/10.1016/j.addma.2018.11.01 3

Nikon metrology NV. (n.d.)Nikon CT Pro 3D. https://www.nikonmetrology.com

Özel, T., Altay, A., Kaftanoğlu, B., Leach, R., Senin, N., \& Donmez, A. (2019). Focus Variation Measurement and Prediction of Surface Texture Parameters Using Machine Learning in Laser Powder Bed Fusion. Journal of Manufacturing Science and Engineering, 142(1). https://doi.org/10.1115/1.4045415

Senin, N., Thompson, A., \& Leach, R. K. (2017). Characterisation of the topography of metal additive surface features with different measurement technologies. Measurement Science and Technology, 28(9). https://doi.org/10.1088/1361-6501/aa7ce2

Soret, M., Bacharach, S. L., \& Buvat, I. (2007). Partial-volume effect in PET tumor imaging. Journal of Nuclear Medicine, 48(6), 932-945. https://doi.org/10.2967/jnumed.106.035774

Sun, S., Brandt, M., \& Easton, M. (2017). Powder bed fusion processes: An overview. Laser Additive Manufacturing: Materials, Design, Technologies, and Applications, 55-77. https://doi.org/10.1016/B978-0-08-1004333.00002-6

Sun, W., Brown, S., \& Leach, R. (2012). NPL REPORT ENG 32 An overview of industrial X-ray computed tomography Sun W, Brown $\mathrm{S} B$ and Leach R K JANUARY 2012. Measurement, January. 
Taylor Hobson. (2002). Cut-offs and the MeasuremenT of Surface Roughness. Retrieved from https://www.taylorhobsonserviceusa.com/up loads/2/5/7/5/25756172/cutoffs_and_the_measurement_of_surface_roug hness.pdf

Thompson, A., Senin, N., Giusca, C., \& Leach, R. (2017). Topography of selectively laser melted surfaces: A comparison of different measurement methods. CIRP Annals Manufacturing Technology, 66(1), 543-546. https://doi.org/10.1016/j.cirp.2017.04.075

Thompson, A., Senin, N., Maskery, I., \& Leach, R. (2018). Effects of magnification and sampling resolution in X-ray computed tomography for the measurement of additively manufactured metal surfaces. Precision Engineering, 53, 54-64. https://doi.org/10.1016/j.precisioneng.2018. 02.014

Townsend, A., Pagani, L., Scott, P., \& Blunt, L. (2017). Areal surface texture data extraction from X-ray computed tomography reconstructions of metal additively manufactured parts. Precision Engineering, 48, 254-264.

https://doi.org/10.1016/j.precisioneng.2016. 12.008

Townsend, A., Senin, N., Blunt, L., Leach, R. K., \& Taylor, J. S. (2016). Surface texture metrology for metal additive manufacturing: a review. Precision Engineering, 46, 34-47. https://doi.org/10.1016/j.precisioneng.2016. 06.001

Townsend, A., Racasan, R., Leach, R., Senin, N., Thompson, A., Ramsey, A., Bate, D., Woolliams, P., Brown, S., \& Blunt, L. (2018). An interlaboratory comparison of X-ray computed tomography measurement for texture and dimensional characterisation of additively manufactured parts. Additive Manufacturing, 23, 422-432. https://doi.org/10.1016/j.addma.2018.08.01 3

Triantaphyllou, A., Giusca, C. L., Macaulay, G. D., Roerig, F., Hoebel, M., Leach, R. K., Tomita, B., \& Milne, K. A. (2015). Surface texture measurement for additive manufacturing. Surface Topography: Metrology and Properties, 3(2). https://doi.org/10.1088/2051$672 \mathrm{X} / 3 / 2 / 024002$

Vandenbroucke, B., \& Kruth, J. P. (2007). Selective laser melting of biocompatible metals for rapid manufacturing of medical parts. Rapid Prototyping Journal, 13(4), 196-203. https://doi.org/10.1108/1355254071077614 2
Vetterli, Marc; Schmid, Manfred; Wegener, K. (2014). Comprehensive investigation of surface characterization for laser sintered parts.

Volume Graphics. (2016). VGStudio MAX. http://www.volumegraphics.com/en/produc ts/vgstudio-max.html

Weckenmann, A., \& Krämer, P. (2013). Computed tomography in quality control: Chances and challenges. Proceedings of the Institution of Mechanical Engineers, Part B: Journal of Engineering Manufacture, 227(5), 634-642. https://doi.org/10.1177/0954405413479849

Zygo Corporation. (2018). Mx Surface Texture Parameters. 28. https://www.zygo.com/library/papers/MxSurface-Texture-Parameters.pdf 